
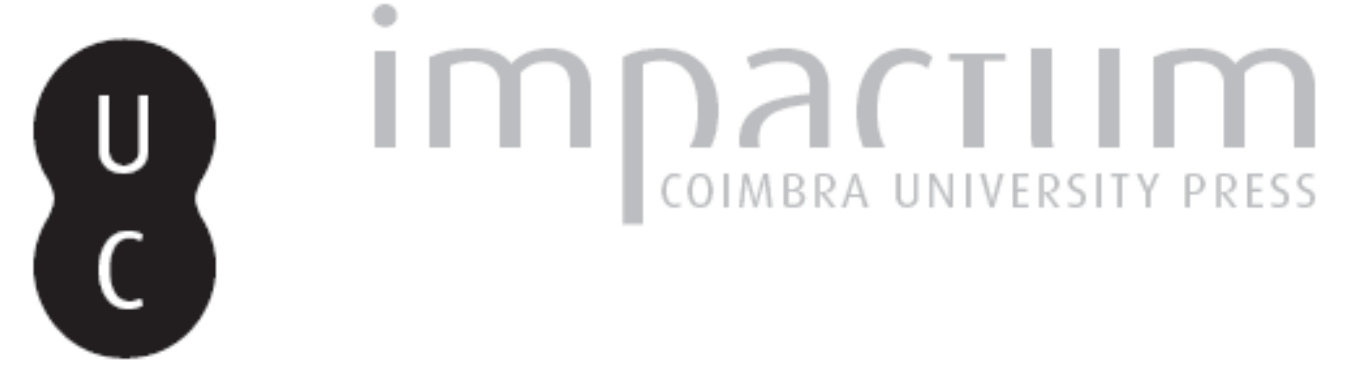

\title{
Contributo para o estudo da tecnologia naval romana, a partir da reconstrução gráfica de um navio tipo Corbita
}

Autor(es): $\quad$ Freire, Jorge; Farinha, Nuno; Fialho, António; Correia, Fernando

Publicado por: Faculdade de Letras da Universidade de Coimbra

URL persistente:

URI:http://hdl.handle.net/10316.2/37754

DOI:

DOI:http://dx.doi.org/10.14195/1647-8657_46_12

Accessed : $\quad$ 26-Apr-2023 10:57:12

A navegação consulta e descarregamento dos títulos inseridos nas Bibliotecas Digitais UC Digitalis, UC Pombalina e UC Impactum, pressupõem a aceitação plena e sem reservas dos Termos e Condições de Uso destas Bibliotecas Digitais, disponíveis em https://digitalis.uc.pt/pt-pt/termos.

Conforme exposto nos referidos Termos e Condições de Uso, o descarregamento de títulos de acesso restrito requer uma licença válida de autorização devendo o utilizador aceder ao(s) documento(s) a partir de um endereço de IP da instituição detentora da supramencionada licença.

Ao utilizador é apenas permitido o descarregamento para uso pessoal, pelo que o emprego do(s) título(s) descarregado(s) para outro fim, designadamente comercial, carece de autorização do respetivo autor ou editor da obra.

Na medida em que todas as obras da UC Digitalis se encontram protegidas pelo Código do Direito de Autor e Direitos Conexos e demais legislação aplicável, toda a cópia, parcial ou total, deste documento, nos casos em que é legalmente admitida, deverá conter ou fazer-se acompanhar por este aviso.

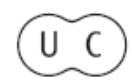




\section{CONIMBRIGA}

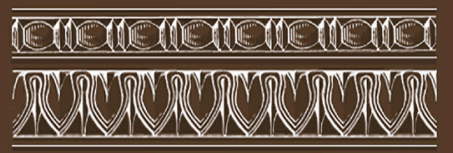

INSTITUTO DE ARQUEOLOGIA

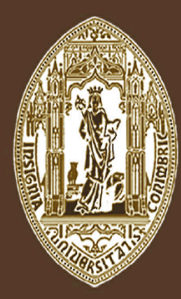

VOLUME XLVI - 2007

FACULDADE DE LETRAS UNIVERSIDADE DE COIMBRA 
Jorge Freire*, Nuno Farinha**, António Fialho* e Fernando Correia**

* Divisão de Museus Municipais do Departamento de Cultura da Câmara Municipal de Cascais

** Ilustradores científicos (www.sciencebyart.com)

CONTRIBUTO PARA O ESTUDO DA TECNOLOGIA NAVAL ROMANA, A PARTIR DA RECONSTRUÇÃO GRÁFICA DE UM NAVIO TIPO CORBITA “Conimbriga" XLVI (2007) p. 281-290

RESUmo: O trabalho gráfico que agora se apresenta resulta de uma sistematização, no sentido da arqueologia experimental, sobre os corbita e as caudicariae enquadrado dentro da perspectiva marítima romana. Mais do que um sumário pretendemos com este exercício contribuir para a consolidação do estudo da problemática da Rota do Atlântico, que durante muito tempo permaneceu secundarizada no contexto da romanização e que actualmente parece ganhar lugar de destaque.

ABSTRACT: The graphic work presented herewith is the result of systematisation according to experimental archaeology, on the corbita and the caudicariae, in the framework of the roman marine perspective. More than a summary, we pretend that this exercise works as a contribution to the consolidation of the Atlantic Route problematic. This has longtime remained secondary in the romanisation context and is presently starting to stand out. 
(Página deixada propositadamente em branco) 


\section{CONTRIBUTO PARA O ESTUDO DA TECNOLOGIA NAVAL ROMANA, A PARTIR DA RECONSTRUÇÃO GRÁFICA DE UM NAVIO TIPO CORBITA}

\section{Introdução}

As técnicas navais romanas resultaram, naturalmente, de múltiplas heranças: primeiro, mediterrânica, fenício-púnica, helénica e etrusca e, posteriormente, também atlântica, céltica ou bárbara. Todas elas permitiram estabelecer uma síntese pragmática no contexto do processo de romanização, entendido como aculturação, das regiões da fachada atlântica. Não só foram pragmáticos como inovadores: navegavam de dia ou de noite, conheciam a vela triangular, sabiam navegar à bolina, mas faziam-no quase sempre com recurso à cabotagem, e estabeleceram uma eficiente e vasta rede de comunicações marítimas, notavelmente conjugada com a rede viária e fluvial.

Navegar na época romana, no Atlântico, tinha três grandes finalidades: uma bélica, para transporte e alimentação das legiões, outra comercial, para transporte e transacção de produtos como os preparados piscícolas, o vinho e o azeite, e por fim para a exploração de recursos naturais, a pesca.

Os navios romanos, relata-nos o Digesta $^{1}$, dividiam-se em três grandes categorias: navios de guerra (naves longae), navios de carga (naves onerariae) e galeras comerciais (naves acturiae). Dentro desta classificação interessa-nos sobretudo desenvolver o tema dos navios de carga porque é sobre eles que, a par dos dados históricos, iconográficos e epigráficos, maiores evidências arqueológicas dispomos, isto porque, a natureza dos produtos transportados em materiais não perecíveis tem

1 Digesta, XLIX, 15, 2. 
possibilitado uma maior e melhor conservação dos restos dos navios romanos em contexto aquático ${ }^{2}$.

\section{Navio Romano do Tipo Corbita}

Os navios romanos eram preferencialmente construídos segundo o processo tipo concha, basicamente de fora para dentro, levantando-se primeiro o forro, formado de pranchas ligeiramente sobrepostas, colocando as pranchas topo a topo, fixadas por meio de encaixes, cavilhas e cunhas, inserindo-se finalmente a ossatura do navio. $\mathrm{O}$ processo concha conferia ao costado um aspecto liso, característico e muito nítido nas representações de navios romanos, nas quais se distinguem as fortes linhas das $\operatorname{cintas}^{3}$ (Ests. 1 e 3 a 7 ).

Todavia, se a preferência do architectus navalis era orientada principalmente para o método concha, tal facto não significa que não tivesse sido utilizado o método em que se construía primeiramente a ossada do navio (esqueleto primeiro) ${ }^{4}$, como sucede nas embarcações regionais do tipo caudicariae encontradas na Britanniae ${ }^{5}$ (Est. 2). Por outro lado, restos de navios como a Madrague de Giens, na ilha de Giens, meados do século I a. C., ou o de Bourse, em Marselha, século I d. C., provam a utilização de um sistema de construção que combinava os dois métodos.

Os navios destinados ao abastecimento e comércio, como os navios do tipo corbita, transportavam e acondicionavam normalmente os produtos em ânforas. $\mathrm{O}$ carregamento principal destes podia ser de um ou vários tipos de ânforas, sugerindo embarque de vários produtos comercializáveis. Alguns navios podiam também transportar artigos secundários, como as sigillatas ou lucernas, como complemento de

2 Agradecemos cordialmente ao Doutor Vasco Gil Soares Mantas o apoio científico na elaboração das ilustrações, ao Dr. António Carvalho a amabalidade de ter feito a revisão do texto, e à Dr. ${ }^{a}$ Ana Guimarães Ferreira pela tradução do abstract.

3 Mantas, Vasco, Tecnologia Naval Romana. Lisboa. Academia de Marinha 1995; Alves, Francisco, “Apontamento sobre um fragmento de tábua de casco de navio dotado do sistema de fixação por encaixe-mecha-respiga, típico da antiguidade mediterrânica, descoberto em 2002 no estuário do rio Arade". Revista Portuguesa de Arqueologia. Volume 8. número 22005 449-457.

4 Gassend, Jean Marie, "La construction naval du type alterné”. Tropis I 1989.

5 McGrail, Seán, "La construction navale celtique". Chasse-Marée, Des Bateaux et des Hommes, n. ${ }^{\circ} 1672001$ 40-53. 
carga e desta forma preencher "os espaços vazios". Porém, os produtos acondicionados não se limitavam às ânforas, mas também eram transportados, no caso do vinho ou de produtos cerealíferos, em tonéis ou em dolias $^{6}$.

Como qualquer outro navio de madeira, iniciava-se a construção do navio tipo corbita ${ }^{7}$ a partir da quilha colocada sobre cepos de madeira, depois ensamblava-se a esta a rabada do navio e a roda de proa. Como forma de definir o casco eram ainda colocadas balizas temporárias (Est. 3, Fig. 1).

A construção do costado iniciava-se com a fixação à quilha das tábuas de resguardo, mediante um número apropriado de encaixes e cavilhas até à borda falsa, altura em que se colocavam as balizas (Est. 3, Fig. 2). Estas eram muito numerosas e colocadas, grosso modo, em intervalos de 25 centímetros. As pranchas do costado eram bastante delgadas, variando entre os $3,5 \mathrm{~cm}$ e os 10 centímetros. As cavilhas de ligação tinham entre 5 a 10 centímetros de largura, em profundidade podiam atingir metade da prancha e intervalavam entre si cerca de 25 centímetros. O processo de colocação das pranchas topo a topo era um processo muito delicado que necessitava de precisão, pois dele dependia a resistência do costado. Os encaixes deveriam ser abertos no topo da prancha, anteriormente fixada, colocando provisoriamente a prancha seguinte para nela se marcarem os encaixes a abrir. A madeira para as pranchas do casco, tendo em conta a operação de encurvamento e o número elevado de encaixes, era cuidadosamente seleccionada, excluindo as muito secas ou as verdes, como forma de prevenir o colapso do costado quando submetido à pressão da água ou da ondulação.

O pé do mastro principal assentava, em muitos dos navios, numa peça de madeira escavada e apoiada na quilha. Nesta cavidade era costume, com fins apotropaicos, colocar uma moeda, a qual, quando recolhida não pode por si só datar o navio, pois podia acontecer a utilização de uma moeda bastante mais antiga como parece ter acontecido no navio Port Vendres II, naufragado em Port Vendres nos Pirinéus Orientais.

Existiam várias formas de construir a ossada no navio. Na representação tridimensional apresentada apostamos numa combinação

6 Pomey, Patrice, La Navigation dans L'Antiquité. ÉDISUD 1997 146-149.

7 Os Corbita tinham no cimo do mastro um cesto, que em latim se designa por corbis. Sobre a etimologia da palavra vide Le Dictionaire des antiquités Grecques et Romaines Daremberg et Saglio Volume I a X 1877/1919 1504-1505. 
mista, tal como o Dramont A do Século I. a. C., que consistia na colocação de balizas contínuas, cravadas ou ensambladas à quilha e à sobrequilha, alternado com balizas, camadas falsas porque partiam da borda falsa e desciam até perto da sobrequilha onde se interrompiam (Est. 4).

A protecção ao casco do navio era feita pelas zosteres (cintas horizontais) que eram poderosas peças de madeira circundantes do navio pelo exterior, fixadas por cavilhas e ligadas internamente a fortes barrotes e à ossada. As latas do convés, tal como os vaus que uniam as balizas, atravessavam o navio de uma banda a outra como reforço da estrutura do casco (Est. 5). O casco podia ainda ser protegido por um revestimento de finas folhas de chumbo, colocado sobre uma cobertura de tecido impermeabilizado, com betume ou resina, fixado com numerosas tachas de cobre de cabeça larga.

O número de pavimentos ou cobertas variava até um máximo de três. Apesar da nossa representação apresentar uma exterior e outra interior, desconhecendo se esta abrangia toda a longitude dos navios. Os pavimentos ou cobertas eram suportados por pés de carneiro ou por pontaletes, centrais ou laterais, contribuindo assim para reforçar a estrutura do casco. Os navios mais pequenos, como as caudicariae, não possuíam convés, substituído por vezes por um passadiço ou tombadilho (Est. 7).

Os navios romanos utilizaram dois tipos de âncora. A âncora com cepo de chumbo (tipo etrusco) deverá ter sido utilizada a partir dos finais do século $\mathrm{V}$ a. C., enquanto que a âncora de ferro (tipo grego) deverá ter sido utilizada a partir dos finais do século III a. C. O século I deve ter assistido ao abandono progressivo da âncora de cepo em chumbo, adoptando-se exclusivamente a âncora de ferro por esta ser de maior funcionalidade ao apresentar um cepo desmontável ${ }^{8}$.

Tecnicamente as âncoras romanas eram constituídas por três partes: o cepo, a cana ou alma e os braços ou patas. Nas âncoras com cepo de chumbo os braços formavam um triângulo isósceles e eram, na maioria dos casos, em madeira, tal como a cana. Os cepos eram em chumbo para conferir maior peso ao conjunto, fixando a âncora ao fundo. Os braços das âncoras em madeira acabavam em pontas de metal sem dentes. As patas eram ligadas à cana por cavilhas de madeira ou por braça-

8 Mercanti, M. P., Ancore Antique, Roma 1979; Kapitän, G., “Ancient anchors. Technology and classification", The International Journal of Nautical Archaeology, 13,1 1984 33-44.

Conimbriga, 46 (2007) 281-290 
deiras de chumbo (Est. 6). Nas âncoras em ferro a diferença estava nos braços serem curvos, e possuir um cepo desmontável, na grande maioria das vezes feito de madeira, ou em algumas raras excepções ser de chumbo ${ }^{9}$.

\section{Comércio e navegação}

A quantidade de produtos transportados variava mediante as necessidades comerciais. Os navios romanos podiam transportar entre 10 toneladas, para navios pequenos, e 400 toneladas para os grandes navios, como parece ter sido o caso do navio romano Madrague de Giens naufragado entre os anos 75-60 a. C. perto da quase ilha de Giens. $\mathrm{O}$ cálculo da tonelagem de um navio antigo revela-se um exercício quanto a nós extremamente difícil de tal modo que as poucas fórmulas apresentadas não são consensuais. Actualmente o cálculo da tonelagem é feito a partir da distinção entre o peso total do navio, que corresponde à capacidade de deslocamento, e o peso da carga. As fontes clássicas são omissas a esta diferenciação para além de contribuírem para o dificultar da tarefa por apresentarem medidas de cálculo variável consoante o produto transportado: para o trigo eram indicados os módios e para as ânforas os talentos ${ }^{10}$. O elemento essencial para o cálculo da tonelagem é o comprimento da quilha conjugado com as fórmulas tradicionalmente utilizadas na construção naval do século XVII e XVIII ${ }^{11}$. Para termos a certeza que as medidas recolhidas para o estudo da produção gráfica do navio em 3D estavam de acordo com as informações transmitidas pelas fontes, efectuámos um simples cálculo: saber quantas ânforas Dressel 14 seria possível introduzir dentro do espaço tridimensionalmente criado. O resultado aproximou-nos de um navio de 258 toneladas de carga, o que se traduz num carregamento de 3688 ânforas (Est. 8) ${ }^{12}$.

9 Mantas, Vasco, Tecnologia Naval Romana. Lisboa. Academia de Marinha 1995 27-28.

101 tonelada $=150$ Módios $=38,5$ Talentos $=20 / 25$ ânforas.

11 Este método foi utilizado e testado no naufrágio de Cavalière ao recorrer a fórmula cuja metrologia assenta no pé do rei francês, ou seja, cerca de $32,5 \mathrm{~cm}$.

$12 \mathrm{O}$ número apresentado forma cálculos de aritmética. As 200 toneladas não tiveram em conta as fórmulas utilizadas para calcular a tonelagem de carga, a tonelagem de deslocação e de lastragem. 
No que diz respeito à navegação, as fontes clássicas reportam-se quase exclusivamente ao Mediterrâneo ${ }^{13}$. Contudo, é possível obter, ainda que indirectamente, dados preciosos sobre o tipo de navegação que poderá ter existido no Atlântico romano, a qual era feita principalmente por meio da cabotagem, com a linha de costa à vista, apoiada por um conjunto de instrumentos náuticos rudimentares e pela experiência adquirida ao longo de todo o período romano, que se traduzia no conhecimento das correntes, ventos e marés, e saber evitar os traiçoeiros escolhos da costa. Estes seriam fundamentais para resistir e compreender as difíceis condições do Atlântico e permitir a evolução da própria noção de mare clausum trazida do Mediterrâneo. A este respeito Vegécio diz-nos: “(...) Todo o conhecimento e todas as artes naturais devem ser postos em prática na previsão dos ventos e das tempestades, através da observação dos céus. Na dureza do mar, do mesmo modo que a precaução protege os evidentes, o desleixo acaba por afogar os descuidados. É por isso que importa conhecer o número e o nome dos ventos. (...) O mar constitui o terceiro elemento do mundo e é agitado, para além da força dos ventos, pela sua própria corrente e movimento. Em determinadas horas do dia e da noite, ocorre um movimento a que chamam maré, que avança e recua; tal como um grande rio que sai do seu leito, também o mar inunda a terra e depois volta a retirar-se. (... $)^{14}$.

Também não podemos esquecer que o mundo romano, contribuindo para a navegação ao longo do Atlântico, não podia dispensar uma rede de portos que permitisse o funcionamento regular de linhas de comunicação e de abastecimentos, por vezes bastantes extensas, essenciais à política de Roma e capaz de servir eficazmente a administração do império orientada a partir de um sistema de economia global. A este propósito Tácito refere: "As fronteiras do Império eram no Oceano ou em rios distantes. Exércitos, províncias, esquadras, todo o sistema estava interligado"15. Dentro desta dinâmica há que reconhecer o estabelecimento de um vasto conjunto de portos secundários ao longo da costa atlântica como um decisivo complemento às grandes rotas comerciais romanas (Est. 9). Os portos eram necessários ao desenvol-

13 Rougé, Jean, La Marine Dans l'Antiquité. Collection SUP, Presses Universitaires de France 1975 10-16.

14 Man, Adriaan de, Tratado de Ciência Militar de Flávio Vegécio Renato. Edições Sílabo 2006 146-148.

15 Tácito, Ann., I, 9. 
vimento económico, e fundamentais para a protecção e abrigo dos navios, como muito bem compreendeu Vegécio: "Os timoneiros e os marinheiros devem conhecer bem os portos e os lugares por onde navegam para evitarem as rochas, os estreitos e os bancos de areia, porque a segurança é tanto maior quanto mais fundo é o mar." 16.

Numa altura em que o estudo da Rota Atlântica ganha um novo vigor não será de mais recordar a importância do mar no apoio à excelência da organização imperial romana, na preservação da pax romana, seguradora das comunicações marítimas e do extraordinário desenvolvimento dos navios de comércio, construídos sem preocupações defensivas, tal como descreve Suetónio a propósito de um encontro entre o navio em que seguia o imperador Augusto e um grande transporte vindo de Alexandria: Certo dia em que bordejava a baía de Puetoli, os passageiros e a tripulação de um navio de Alexandria, que acabava de aportar, todos de branco, coroados de flores e queimando incenso, cumularam-no de votos de felicidade e de extraordinários louvores, dizendo ser graças a ele que viviam, graças a ele que navegavam, graças a ele que gozavam de liberdade e de prosperidade ${ }^{17}$.

\section{BIBLIOGRAFIA}

Alves, Francisco, "Apontamento sobre um fragmento de tábua de casco de navio dotado do sistema de fixação por encaixe-mecha-respiga, típico da antiguidade mediterrânica, descoberto em 2002 no estuário do rio Arade”. Revista Portuguesa de Arqueologia. Volume 8. número 22005 449-457.

ALVEs, Francisco et alii, "Os cepos âncora em chumbo descobertos em águas portuguesas. Contribuição para uma reflexão sobre a navegação ao longo da costa atlântica da Península Ibérica na Antiguidade”, «O Arqueólogo Português», série IV 1988-1989 6-7.

CAsson, Lione, Ships and Seamanship in the Ancient World. Princeton 1973.

Coles, John, Arqueologia Experimental. Bertrand 1973.

GASSEnd, Jean Marie, "La Construction Naval Du Type Alterné". Tropis I 1989.

KAPITÄN Gerhard, “Ancient anchors. Technology and classification”, The International Journal of Nautical Archaeology, 13,1 1984 33-44.

PARKER, Anthony John, Anciente shipwrecks of the Mediterranean and the Roman provinces, Oxford 1992.

16 Man, Adriaan de, Tratado de Ciência Militar de Flávio Vegécio Renato. Edições Sílabo 2006148.

17 Suetónio, Aug., 98. 
PomeY, Patrice, La Navigation dans L'Antiquité. ÉDISUD 1997.

Man, Adriaan de, Tratado de Ciência Militar de Flávio Vegécio Renato. Edições Sílabo 2006.

Mantas, Vasco, Tecnologia Naval Romana. Lisboa. Academia de Marinha 1995.

Mantas, Vasco, Portos Marítimos Romanos. Lisboa. Academia de Marinha 2000.

Mantas, Vasco, "O Atlântico e o Império Romano”. Revista Portuguesa de História. Instituto de História Económica e Social, Faculdade de Letras da Universidade de Coimbra, Tomo XXXVI, Volume 2 2002/2003 445-467.

MantAs, Vasco, “A Lusitânia e o Mediterrâneo: Identidade e diversidade numa província romana”. Conimbriga XLIII 2004 63-83.

McGrail, Seán, "La construction navale celtique". Chasse-Marée, Des Bateaux et des Hommes, n. ${ }^{\circ} 1672001$ 40-53.

Mercanti, Micaela Perrone, Ancore Antique, Roma 1979.

RIETH, Éric, Le Maître-Gabarit, La Tablette et le Trébuchet. Essai sur la conception non-graphique des carènes du Moyen Âge au XX Siècle. Éditions du CTHS 1996.

RIVAL, Michel, La Charpanterie Naval Romaine, Paris, 1991.

Rougé, Jean, La Marine dans L'Antiquité. Collection SUP, Presses Universitaires de France 1975. 
EsT. I

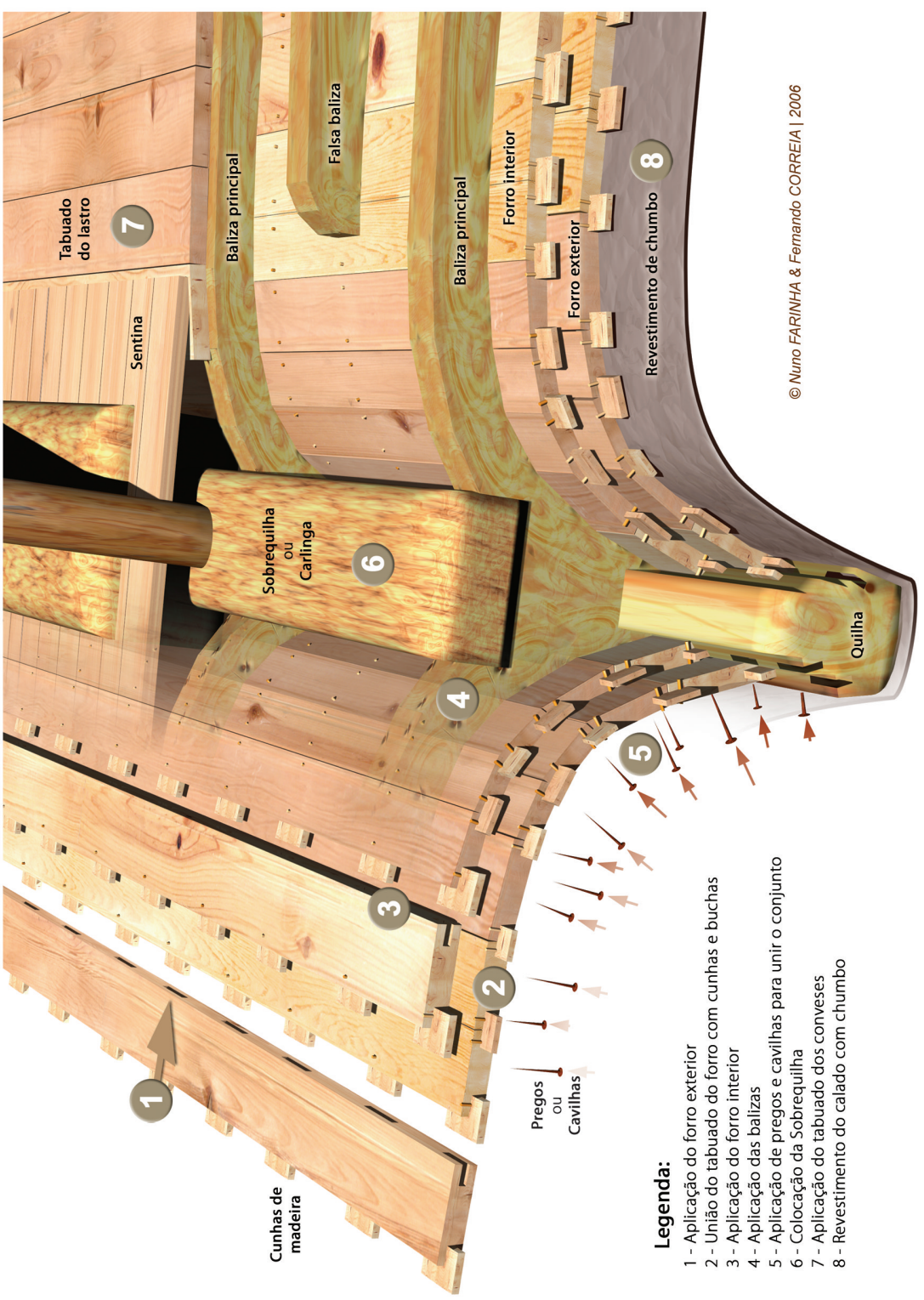


EST. II
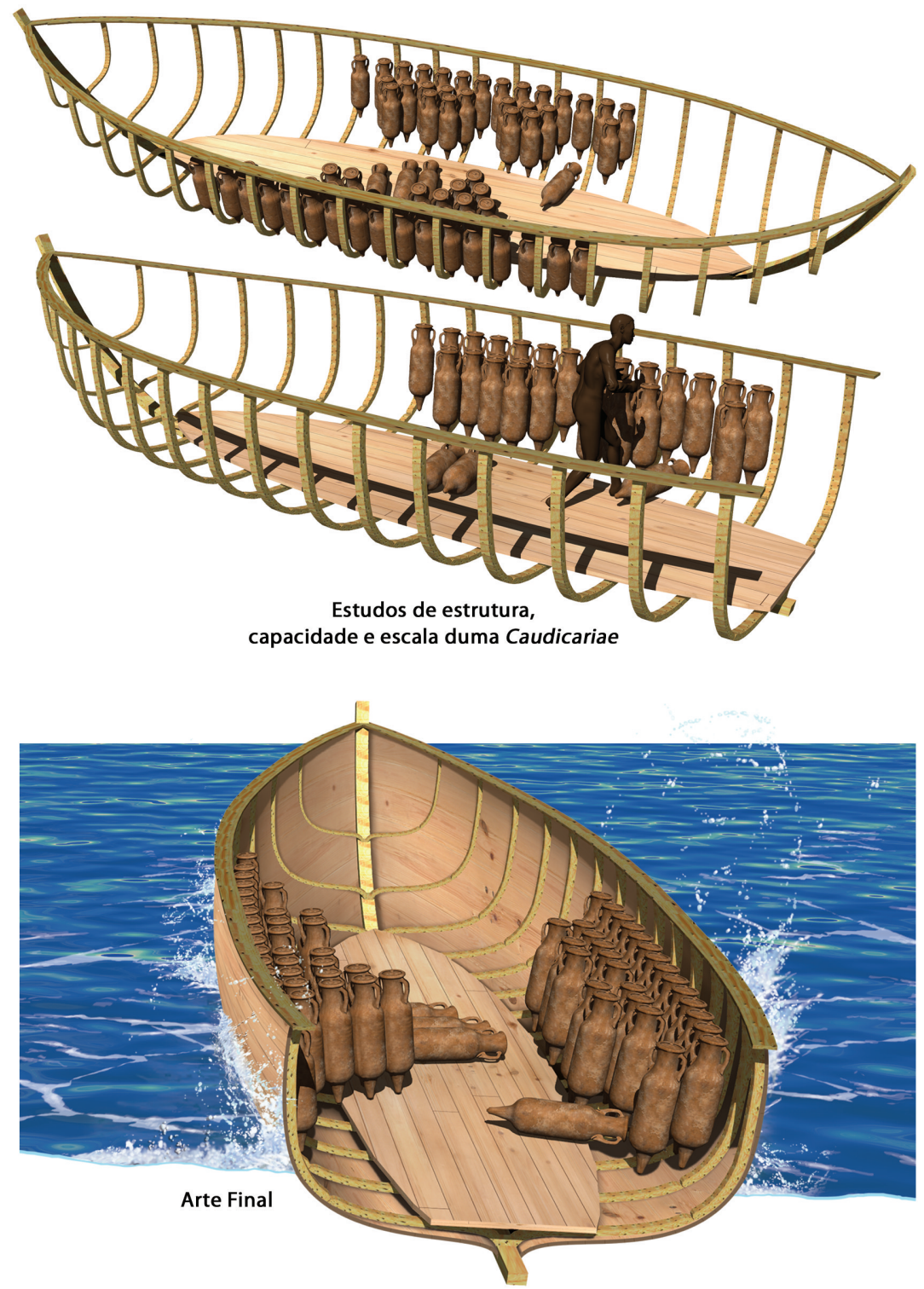

(C) Nuno FARINHA \& Fernando CORREIA | 2006 
EsT. III
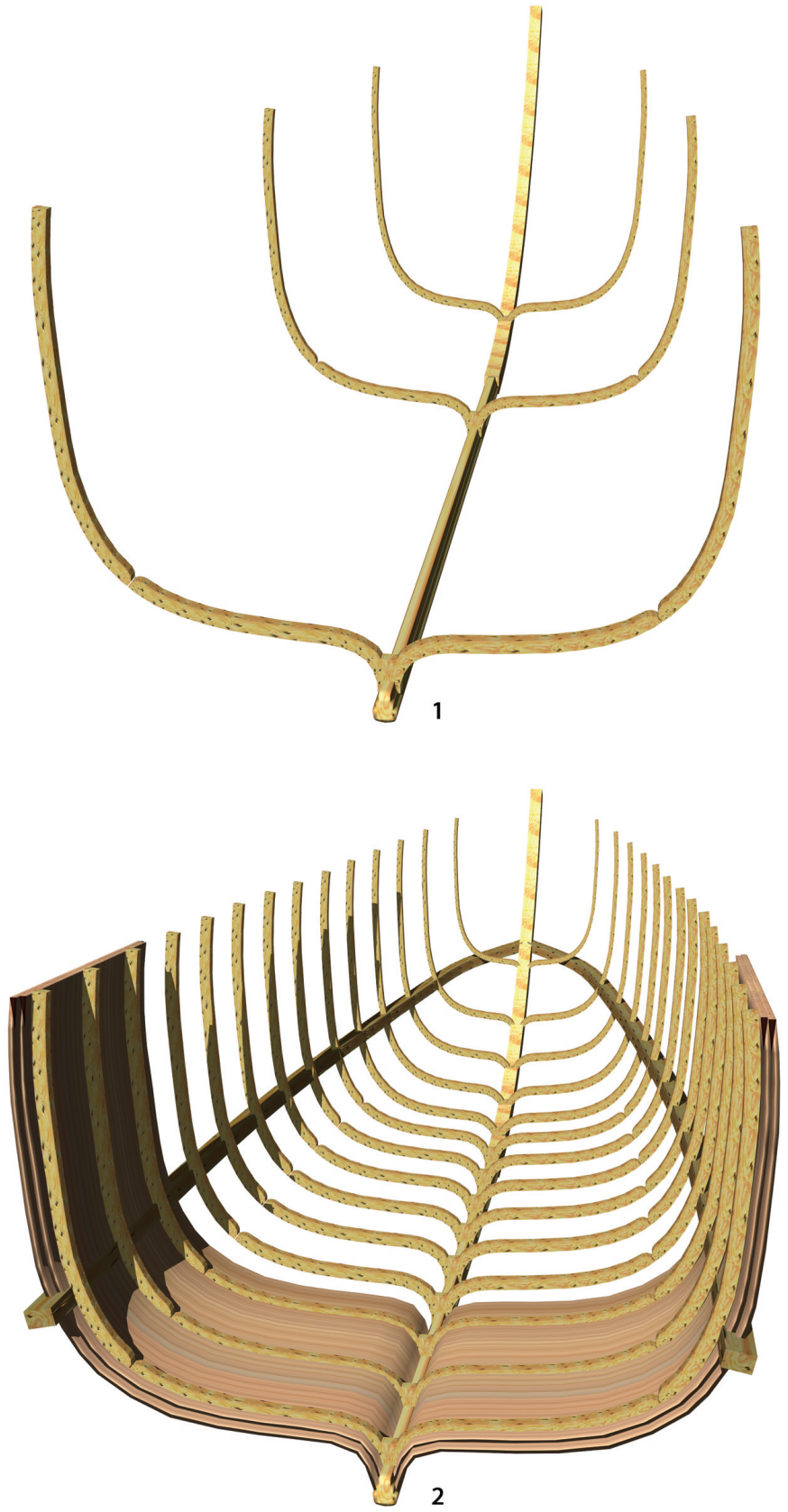
EsT. IV
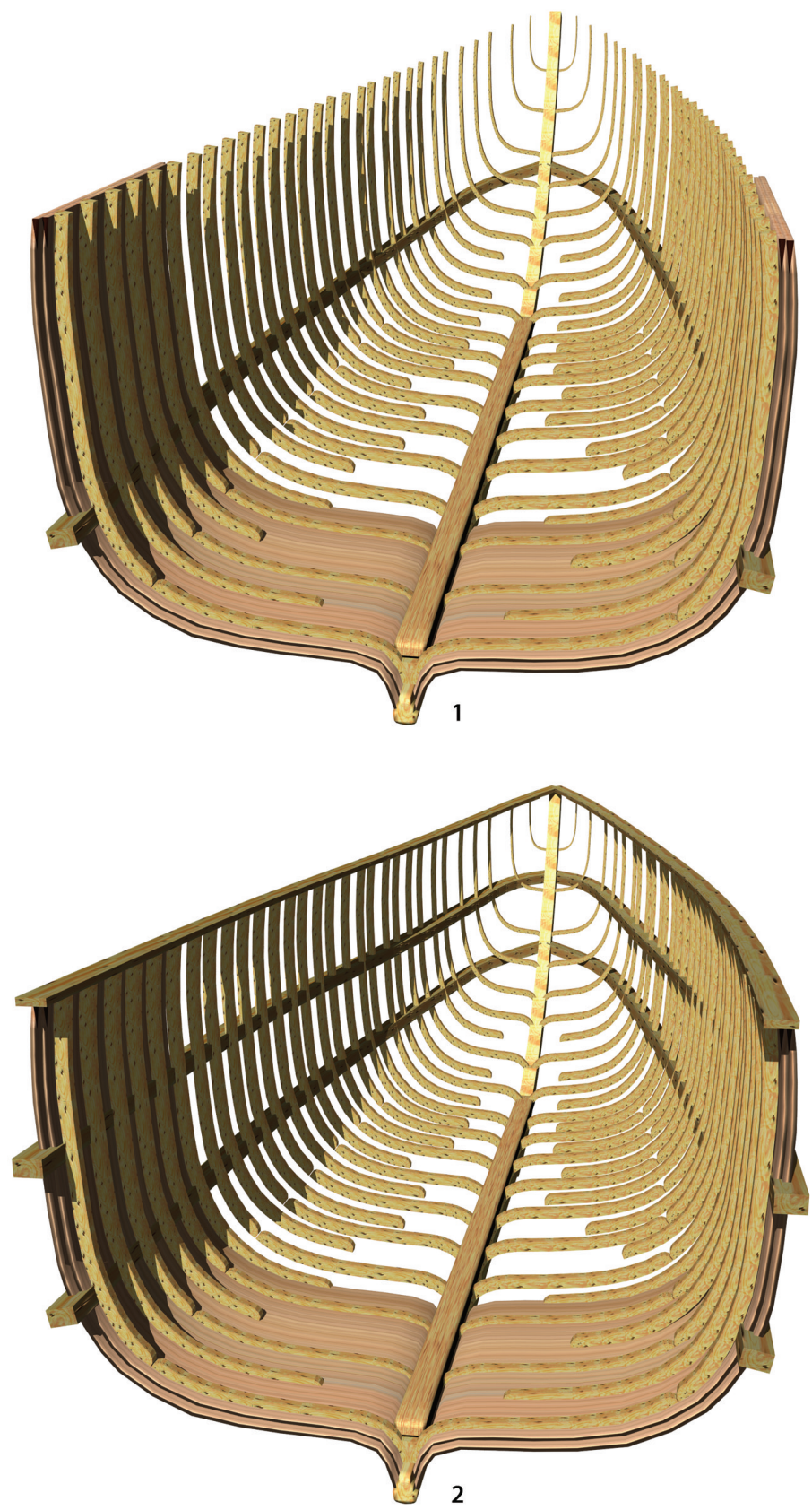
EsT. V

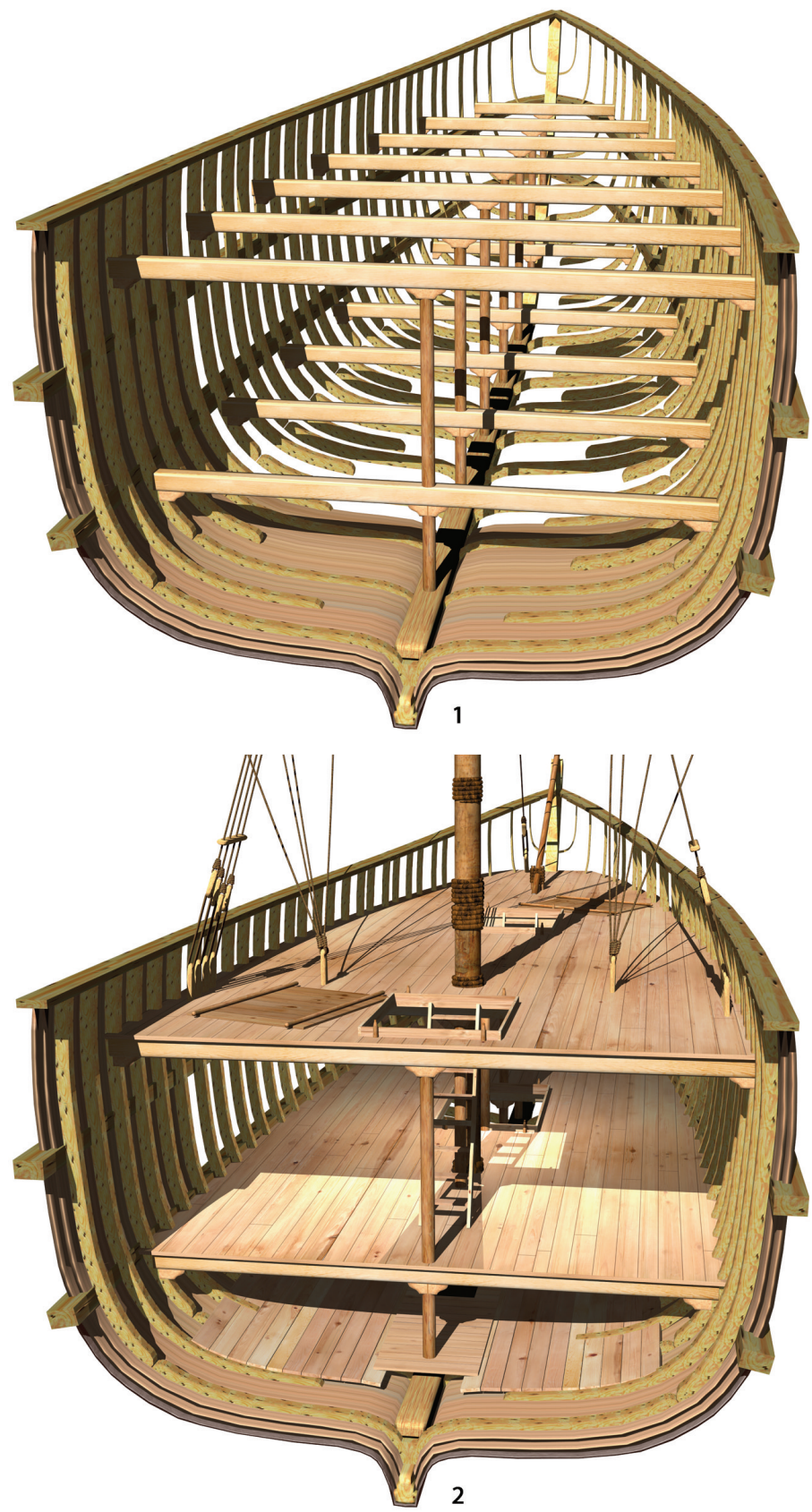


EsT. VI

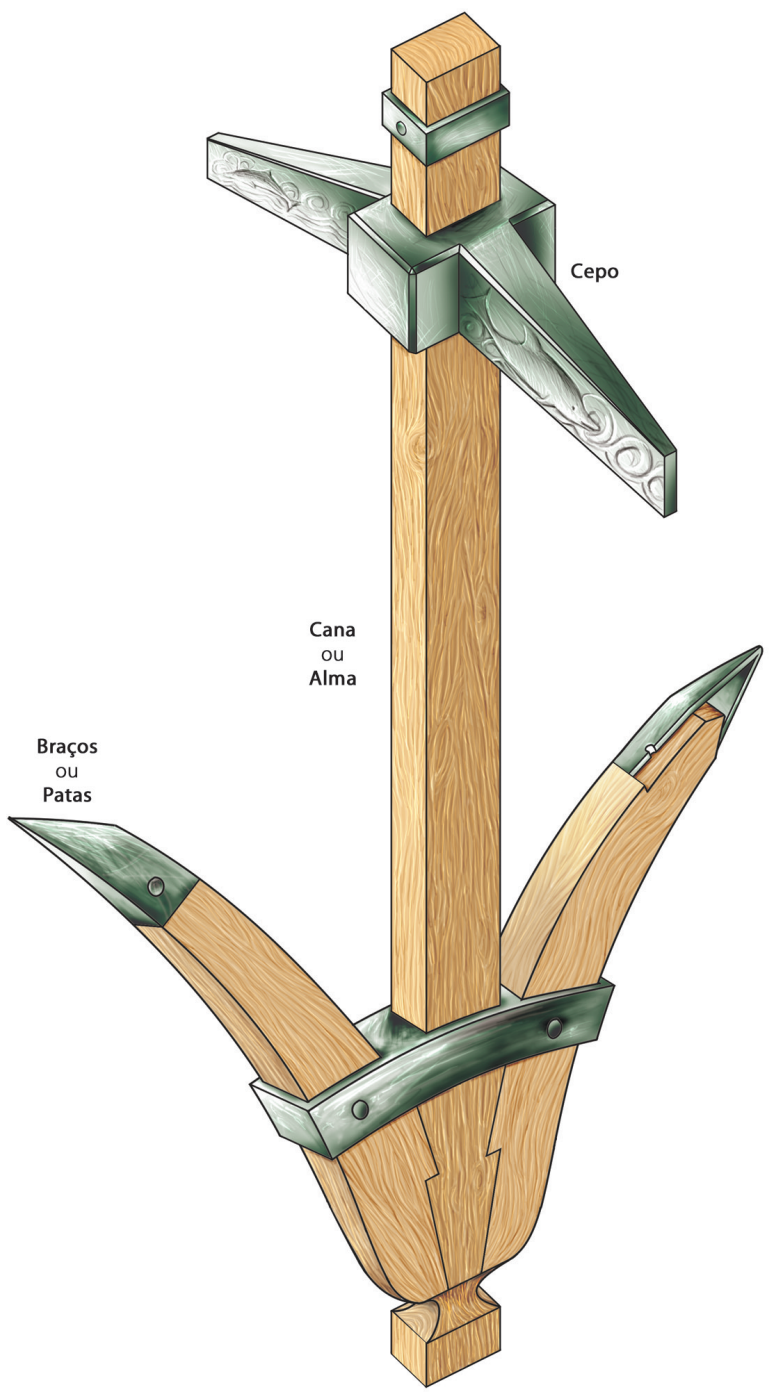

(c) Fernando CORREIA \& Nuno FARINHA | 2006 
EsT. VII

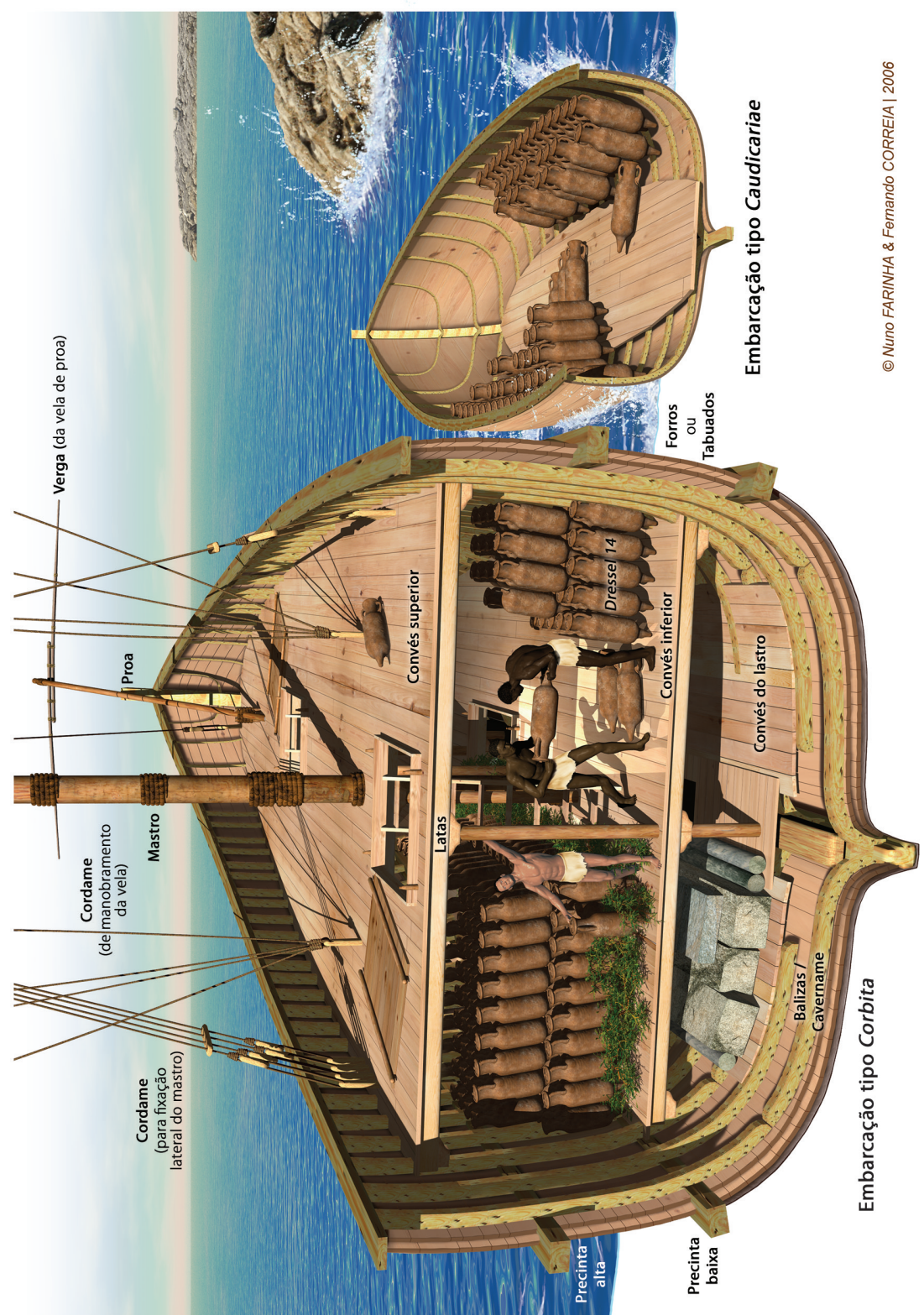


EsT. VIII

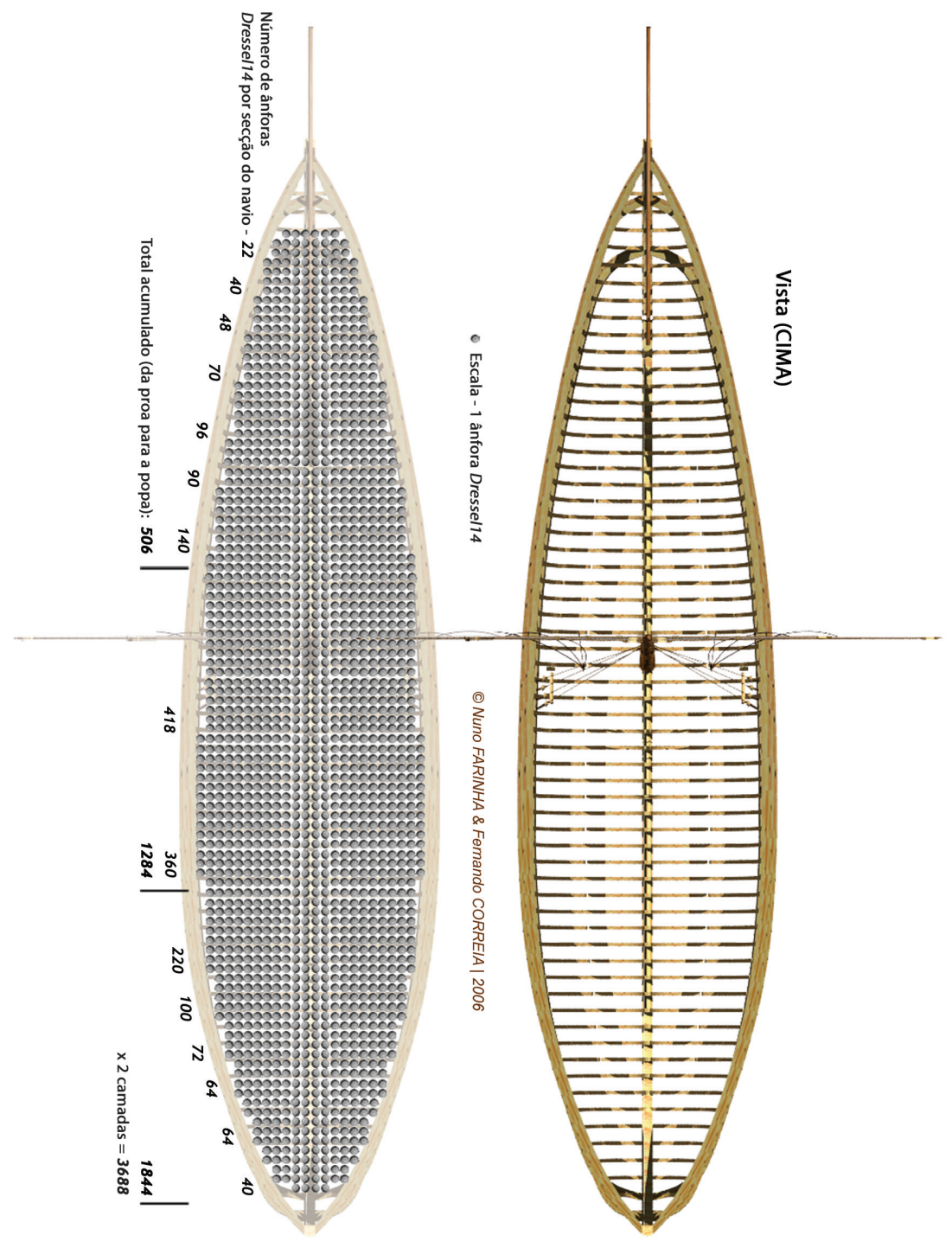


EsT. IX

\section{Duração Rotas Marítimas}

Gades - Ostia (9 dias)

Arles - Alexandria (30 dias)

Ostia - Alexandria (16 a 20 dias)

Ostia - Caesarea (20 dias)

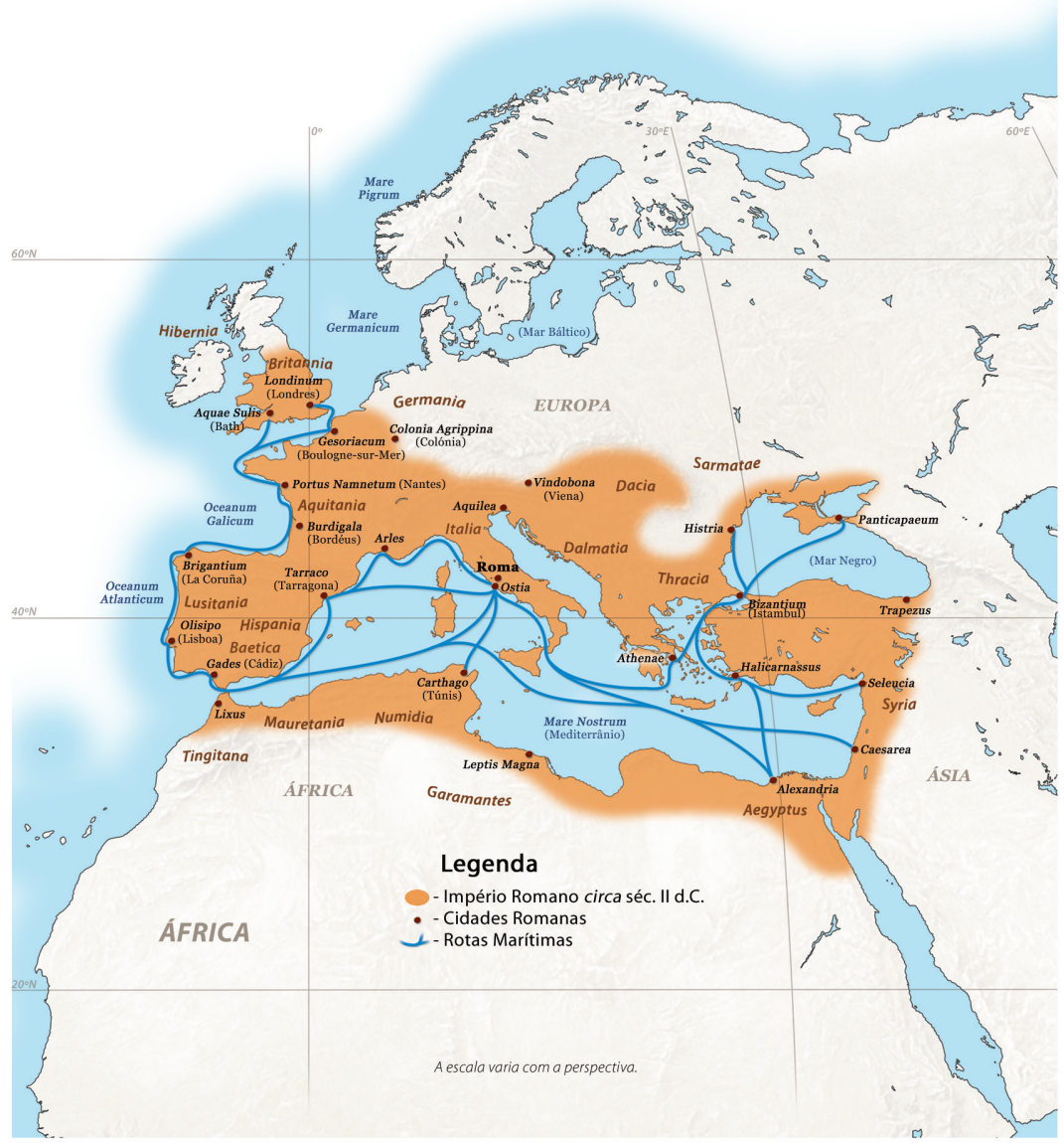

FONTE: Beltrán Lloris \& Marco Simón (1987) - Atlas de Historia Antigua

Atlas da História do Mundo (1999) from "The Times History of the World" 